\title{
Association Between Blood Groups and Myopia Among Medical Students of Fatima Jinnah Medical University \\ ${ }^{1}$ Shazo Sana, ${ }^{1}$ Shireen Khawar, ${ }^{2}$ Hafiz Muhammad Umair, ${ }^{1}$ Ghazala Naveed, ${ }^{1}$ Maryam Rao \\ ${ }^{I}$ Department of Physiology, Fatima Jinnah Medical University, Lahore \\ ${ }^{2}$ Department of Hematology, Fatima Jinnah Medical University, Lahore
}

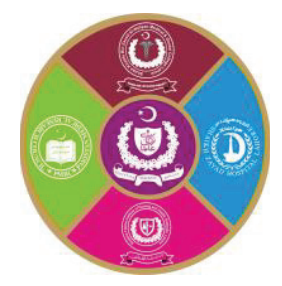

\begin{abstract}
Introduction: Blood grouping is not only important for transfusions but also because blood groups have been associated with different diseases including eye diseases. Myopia, the near sightedness is the most common among other types of refractive errors. Regarding etiology of myopia, the contributing factors include both environmental and genetic factors. Research is still going on to find other risk factors for development of myopia. Aims \& Objectives: The present study was planned to find out the association of myopia and ABO blood groups in medical students of Fatima Jinnah Medical University (FJMU). This study may help to identify the subject at risk of being developing myopia. Place and duration of study: This cross sectional study was conducted at FJMU from March 2018 to May 2018. Material \& Methods: After taking ethical clearance from Physiology Department of FJMU and informed consent from $2891^{\text {st }}$ year MBBS students, Snellen's eye chart was used to examine visual acuity. Blood groups were determined by slide method. Data was analyzed by SPSS-21. Chi square test of association was done. Results: Out of 289, 181 students were myopics and 108 were non myopics. So, the frequency of myopia was $62.6 \%$. The most prevalent blood group was $\mathrm{B}+(35 \%)$ followed by $\mathrm{O}+(25 \%), \mathrm{A}+(20 \%)$ and $\mathrm{AB}+(9 \%)$. It was found that the frequency of occurrence of myopia was highest in blood group $\mathrm{O}(49 \%)$ then $\mathrm{B}(32 \%)$ followed by $\mathrm{A}(20 \%)$ and $\mathrm{AB}(8 \%)$. Chi square test of association was applied and result showed a statistically significant association between myopia and blood groups $(\mathrm{p}<0.05)(\mathrm{df}=1)$. There was highest relative risk of myopia in blood group $\mathrm{O}(1.73)$. Conclusion: Blood groups showed statistically significant association with myopia. The chances of occurrence of myopia are highest in blood group $\mathrm{O}$.
\end{abstract}

Key words: blood groups, myopia, medical students

\section{INTRODUCTION}

$\mathrm{T}_{\mathrm{h}}$ he concept of blood groups was first given by K. Landsteiner in 1901. He described that RBCs have antigens on their surfaces. Depending on the presence of these antigens, he classified blood into 4 groups, $\mathrm{A}, \mathrm{B}, \mathrm{AB}$ and $\mathrm{O}^{1}$. Blood grouping is not only important for transfusions but also because blood groups has been associated with different diseases including eye diseases. ${ }^{2}$

There are different types of refractive errors, myopia, hypermetropia and astigmatism. Among these, Myopia is the commonest one. In myopia, the increased axial length of eye ball causes the parallel rays of light to be focused in front of retina resulting into formation of blurred image ${ }^{3}$. Many factors are responsible for causing myopia including both controllable and uncontrollable factors. The controllable factors include physical activities, diet and habits while uncontrollable factors are genetics and age $e^{4,5,6,7}$. Research is still in process to identify different unknown environmental and genetic factors in the pathogenesis of myopia as it is associated with increased risk of blindness resulting from retinal detachment, choroid angiogenesis and lens degeneration. In addition, myopia is also associated with increased risk of cataract and glaucoma ${ }^{8}$. Many researchers have shown the association of $\mathrm{ABO}$ blood groups with eye diseases as a study conducted by Gupta and Nishi in 2015 in India showed association $\mathrm{b} / \mathrm{w}$ blood groups and myopia and found that the highest risk of occurrence of myopia was seen in blood group $\mathrm{O}^{9}$. Another study from India showed the association $\mathrm{b} / \mathrm{w}$ blood groups and myopia with lowest risk of occurrence of myopia in blood groups $\mathrm{O}$ as compared to $\mathrm{A} / \mathrm{B} / \mathrm{AB}$ blood groups ${ }^{10}$. In our country, there is only one study conducted by Hussain and Zahra on 40 myopic patients and showed that individuals having 
O blood group have slight pre dominance to myopia with non significant results ${ }^{11}$. Thus the above literature showed contradictory results and there is lack of work regarding association of myopia and blood groups in other parts of the world as well as in our country. So, the present study is planned to find out if there is any association between myopia and ABO blood groups among medical students of FJMU. This study may help to identify the children with a particular blood group at the risk of myopia. There is likelihood that by avoiding controllable risk factors like physical activities, diet and excessive near work such as, writing, reading, computer or smart phone usage and playing video games, they can be saved from myopia and its complications.

\section{MATERIAL AND METHODS}

The current cross-sectional study was done on 289 undergraduate students of $1^{\text {st }}$ and $2^{\text {nd }}$ year MBBS after taking informed consent from students and ethical clearance from the research ethical committee, FJMU.

Sampling technique: Non probability purposive sampling.

Inclusion criteria/Exclusion criteria: Students having other eye diseases such as hypermetropia, astigmatism or any other eye related problems were excluded from the study.

Measurement of refractive errors: The refractive error of the study subjects were determined by using Snellen's eye chart that was placed at a distance of 6 meters from the eye of the subject. Myopia was defined by refractive error of -0.50 . Myopia was additionally classified as mild $=\mid<-1.5$, moderate $<-3$ and severe $=/>-3.12,13$

Blood group determination: Blood group was determined by Haem agglutination rapid slide method using anti sera A, B and D.

\section{Statistical analysis:}

Data was entered and analyzed by SPSS 21 . The categorical variables were presented as frequencies and percentages. The continuous variables were expressed by using mean \pm SD. Chi square test of association was applied to find association $b / w$ blood groups and myopia. Relative risk was calculated to find the blood group having highest risk of getting myopia. p- Value less than 0.05 was considered statistically significant.

\section{RESULTS}

This study was done on $289,1^{\text {st }}$ and $2^{\text {nd }}$ year medical students of FJMU. Out of which 181 were myopic
$(62.6 \%)$ and 108 (37.3\%) were non myopics. Among the study participants, 28 (16\%) were mildly myopic, 84 (46\%) were moderate and 69 (38\%) had severe myopia as shown in Table- 1 . B + was the most prevalent blood group in study population $(35 \%)$ followed by $\mathrm{O}+(25 \%)$ as shown in Fig-1. When the distribution of blood group was seen in myopics (181 students), the most prevalent blood group was found to be $\mathrm{O}+$ in $\mathrm{Rh}+$ blood groups and $\mathrm{O}$-ve in $\mathrm{Rh}$ - blood groups as shown in Fig-2. While in non myopics, most prevalent blood group was found to be B+ as depicted in Fig-3. Chi square test of association was applied to find the association of blood group with myopia, the result showed highest frequency of occurrence of myopia was seen in blood group $\mathrm{O}$ with $\mathrm{p}$ value of 0.001 showing that this association was statistically highly significant. The relative risk of occurrence of myopia with different blood group was calculated by constructing $2 \times 2$ tables and result showed that highest risk was found in blood group $\mathrm{O}$ as shown in Table-2.

\begin{tabular}{|c|c|c|c|c|c|}
\hline $\begin{array}{c}\text { Degree of } \\
\text { myopia }\end{array}$ & N (\%) & Mean & $\begin{array}{c}\text { Std. } \\
\text { Deviation }\end{array}$ & Max. & Min. \\
\hline $\begin{array}{c}\text { Mild } \\
\text { myopia }\end{array}$ & $\begin{array}{c}28 \\
(16 \%)\end{array}$ & -.9750 & .5420 & -1.56 & .50 \\
\hline $\begin{array}{c}\text { Moderate } \\
\text { myopia }\end{array}$ & $\begin{array}{c}84 \\
(46 \%)\end{array}$ & -2.598 & .4873 & -2.34 & -1.35 \\
\hline $\begin{array}{c}\text { Severe } \\
\text { myopia }\end{array}$ & $\begin{array}{c}69 \\
(38 \%)\end{array}$ & -4.945 & 1.290 & -10.00 & -3.00 \\
\hline
\end{tabular}

Table-1: Distribution of varying degrees of myopia $(n=181)$

\begin{tabular}{|c|c|c|c|c|}
\hline \begin{tabular}{|c} 
Blood \\
groups
\end{tabular} & $\begin{array}{c}\text { Myopia } \\
181(63 \%)\end{array}$ & \begin{tabular}{|c|} 
Non \\
Myopia \\
$108(37 \%)$
\end{tabular} & $\begin{array}{c}\text { Relative Risk } \\
\text { of occurrence } \\
\text { of myopia }\end{array}$ & $\begin{array}{c}\text { Chi- square } \\
\text { test } \\
\text { P- value }\end{array}$ \\
\hline $\mathrm{A}$ & $38(20 \%)$ & $27(25 \%)$ & 0.92 & \multirow{4}{*}{$\begin{array}{c}0.001 * * \\
\mathrm{df}=1\end{array}$} \\
\hline B & $58(32 \%)$ & $55(51 \%)$ & 0.73 & \\
\hline $\mathrm{AB}$ & $16(8 \%)$ & $13(12 \%)$ & 0.87 & \\
\hline $\mathrm{O}$ & $89(49 \%)$ & $15(13 \%)$ & $1.73^{*}$ & \\
\hline
\end{tabular}

Table-2: Association of blood groups with myopia irrespective of $\mathrm{Rh}$ factor found by chi square test of association and Relative risk of occurrence of myopia found by $2 \times 2$ tables.

* value greater than 1 shows highest risk

** less than 0.05 is significant 


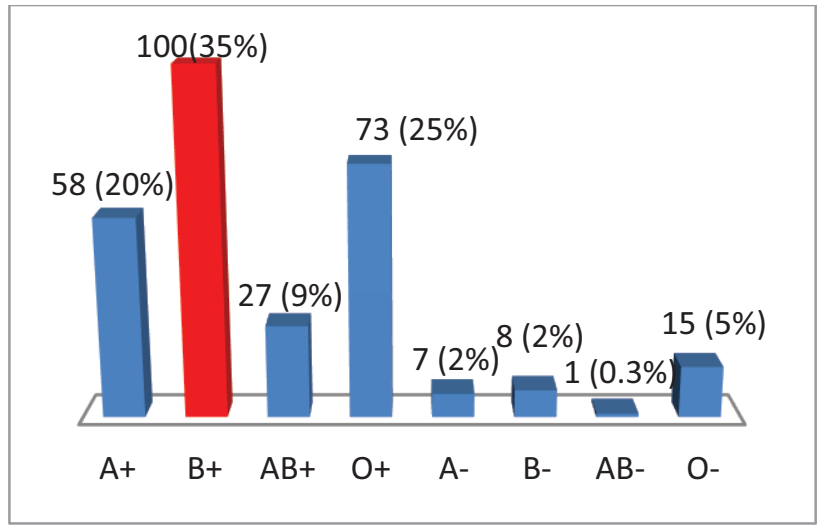

Fig-1: Distribution of blood groups in study population expressed in frequency $(\%)(n=289)$

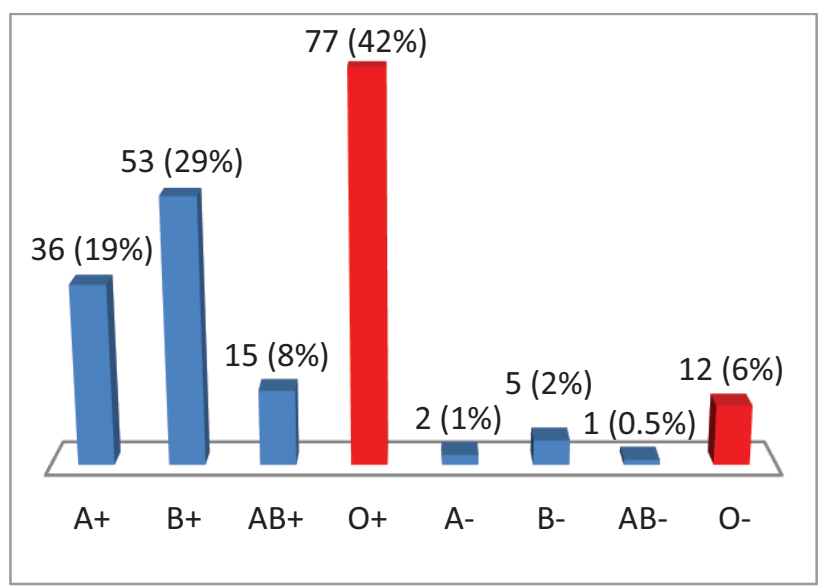

Fig-2: Distribution of $\mathrm{ABO}$ blood groups in myopics expressed in frequency $(\%)(n=181)$

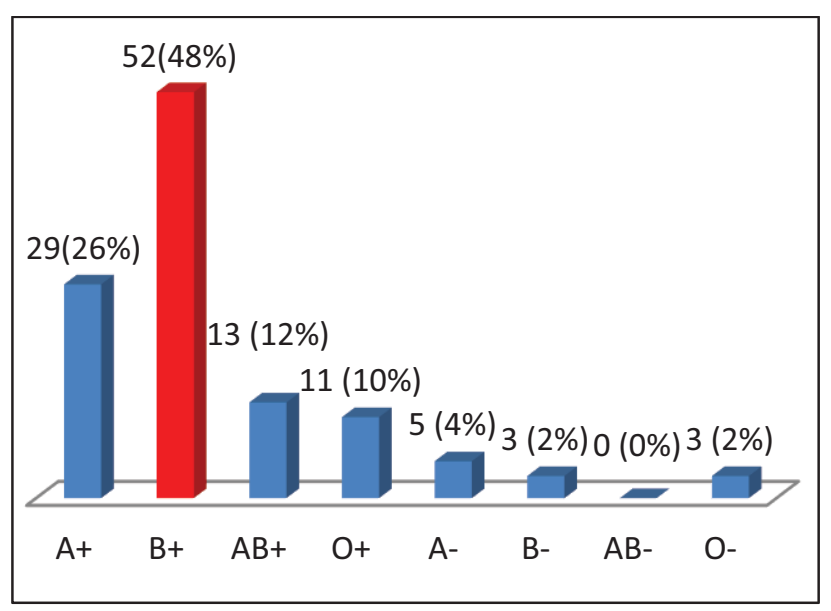

Fig-3: Distribution of ABO blood groups in non myopics expressed in frequency $(\%)(\mathrm{n}=108)$

\section{DISCUSSION}

Refractive errors are the focal cause of decreased visual acuity. Myopia is the most common refractive error among others. High myopia is a hazardous condition as it results in retinal detachment, macular degeneration and cataract at an early age. ${ }^{14}$
The result of the current study shows a high prevalence of myopia in medical students of FJMU $(62.6 \%)$. This is in line with the work done by Parveen et. al. in Karachi ${ }^{15}$. They found the prevalence of myopia to be $47 \%$ among 457 medical students. Similarly Khan et. al. have found a high prevalence of myopia (68\%) among 100 medical students in Nishtar Medical University in Multan ${ }^{16}$. Furthermore, the prevalence of myopia was 53.5\% among 504 medical students in Saudi Arabia ${ }^{17}$. It can be concluded that the medical students have high prevalence of myopia which may be due to increased stress on eyes due to excessive near work in the form of reading ${ }^{18}$.

The distribution of $\mathrm{ABO}$ and $\mathrm{Rh}$ blood groups varies all over the world in different races ${ }^{19}$. The concept of blood grouping is used not only in blood transfusion; it is essential in determining migration of races and hereditary diseases. Some diseases are more common in certain blood groups; hence relationship of different blood groups with diseases is vital. Studies conducted in different areas of Pakistan show the incidence of $\mathrm{ABO}$ and $\mathrm{Rh}$ blood groups in different regions ${ }^{20}$ as a study showed that $\mathrm{O}$ blood group was most prevalent blood group in Sindh $(36 \%)$ followed by blood group B $(30 \%) .{ }^{21}$ Similarly a study conducted in "Baluchistan" reported blood group $\mathrm{O}$, the most prevalent blood group $(37.07 \%)$ followed by group B $(34.32 \%)$, groups A (21.12\%) and blood group AB (7.57\%). ${ }^{22}$ While a study from Rawalpindi and Islamabad had shown the blood group B as the most prevalent blood group $(32.87 \%)$ then blood group $\mathrm{O}$ (31.91\%), blood group A (24.02) and blood group $\mathrm{AB}(11.2 \%){ }^{23}$ In our study, group $\mathrm{B}$ was more prevalent. The students with blood group B were 100 (35\%), followed by group O 73(25\%), group A $58(20 \%)$ and group AB 27(9\%). The result of the current study indicated that the highest frequency of myopia was in blood group $\mathrm{O}+$ in $\mathrm{Rh}$ positive blood groups and $\mathrm{O}-$ in $\mathrm{Rh}$ negative blood groups. This association was statistically significant $(p<0.001)$ with the highest relative risk of myopia found in blood group O (1.73). Similar study has been conducted by Gupta and Nishi in India on 340 myopic individuals. Their results showed the most prevalent blood group in their population was B blood group and highest frequency of occurrence of myopia was seen in B blood group with highest relative risk of occurrence of myopia found in blood group O. ${ }^{9}$ In our country, only one study conducted by Hussain and Zahra in Pakistan on 40 myopic patients showed that individuals having $\mathrm{O}$ blood group have slight preponderance towards myopia. ${ }^{11}$ While another study from India conducted by Ankur 
and Desi in 2015 contradict our finding. ${ }^{10}$ They found the association of myopia and blood groups in 401 myopic patients from hospital setting and concluded that the frequency of occurrence of myopia was less in blood group $\mathrm{O}$ than $\mathrm{A} / \mathrm{B} / \mathrm{AB}$ blood types.

The precise cause of highest frequency of myopia and increased risk of being myopics in blood group $\mathrm{O}$ individual is not known. The current study may show that the presence of $\mathrm{A}$ and $\mathrm{B}$ rhesus antibodies increases the risk of myopia as indicated by the increased frequency of myopia in blood group $\mathrm{O}$ possessing both $\mathrm{A}$ and $\mathrm{B}$ rhesus antibodies. After blood group $\mathrm{O}$, the frequency of myopia was seen in blood group $\mathrm{B}$, having anti body $\mathrm{A}$ followed by blood group A, possessing B antibody. The frequency of myopia was the lowest in blood group $\mathrm{AB}$ containing no antibodies. So, we can say that the absence of rhesus antibodies A and B may be a protective factor for myopia.

\section{CONCLUSION}

- Most prevalent blood group in our study population was $\mathrm{B}+$.

- The highest frequency of myopia was seen in blood group $\mathrm{O}+$ in $\mathrm{Rh}+$ and $\mathrm{O}-$ in $\mathrm{Rh}-$ blood groups with statistically significant association ( $\mathrm{p}$ value $<0.05$ ).

- The highest relative risk of occurrence of myopia was seen in blood group $\mathrm{O}$.

\section{Recommendations:}

It is essential to create awareness among the public that children with blood group $\mathrm{O}$ are at high risk of developing myopia as compared to other blood groups so they should be given special attention to avoid excessive near work such as writing, reading, computer or smart phone usage and playing video games and should take good diet and adopt physical activities to prevent development of myopia.

\section{REFERENCES}

1. Owen R. Karl Landsteiner and the first human marker locus. Genetics. 2000; 155(3):995-998.

2. Anstee DJ. The relationship between blood groups and disease. Blood. 2010; 115(23):46354643.

3. Mutti DO, John R. Hayes JR, Mitchell GL, Lisa A et. al. Refractive error, axial length, and relative peripheral refractive error before and after the onset of myopia. Invest Ophthalmol Vis Sci. 2007; 48(6): 2510-2519.

4. O'Donoghue L, Kapetanankis VV, McClelland JF, et al. Risk factors for childhood myopia: findings from the NICER study. Invest Ophthalmol Vis Sci. 2015; 56:1524-1530.

5. Pan CW, Ramamurthy D, Saw SM. Worldwide prevalence and risk factors for myopia. Ophthalmic Physiol Opt. 2012; 32:3-16.

6. Huang HM, Chang DST, Wu PC. The Association between Near Work Activities and Myopia in Children - A Systematic Review and MetaAnalysis. PLoS ONE. 2015; 10(10): e0140419.

7. Teasdale TW, Fuchs J, Goldshmidt E. Degree of myopia in relation to intelligence and educational level. Lancet. 1988; 2:1351-1354.

8. Saw SM. How blinding is pathological myopia? J Ophthalmol. 2006 May; 90(5):525-6.

9. Gupta NK, Nishi K. A study on the incidence of myopia and hypermetropia in $\mathrm{ABO}$ blood groups. Natl. J. Life Sci. 2013; 10(1): 31-33.

10. Ankur, Desai JUH. Incidence of emmetropics and myopics in abo blood groups. Int $\mathrm{J}$ Basic Appl Physiol. 2015; 4(1): 149-151.

11. Zahra M, Hussain A. Association between blood groups and refractive errors. Ophthalmology. 6(2): 26-28.

12. Kwon JW, Choi JA, La TY. Serum 25hydroxyvitamin D level is associated with myopia in the Korea national health and nutrition examination survey. Medicine (Baltimore). 2016 Nov; 95(46):e5012.

13. Choi JA, Han K, Park YM, La TY. Low serum 25-hydroxyvitamin D is associated with myopia in Korean adolescents. Invest Ophthalmol Vis Sci. 2014 Apr3; 55(4): 2041-7

14. Ikuno, Yasushi MD. An overview of the complications of high myopia. Retina. 2017; 37(12): 2347-2351.

15. Parveen N, Hassan SH, Rehman J, Shoukat U. Prevalence of myopia and its associated risk factors in local medical students. MC. 2015; 21(4): 47-50.

16. Khan FA, Mehmood W, Shaddad AAA. Frequency of myopia and underlying factors of myopia among medical student at Nishtar Medical University. Wjpmr. 2018; 4(9): 24- 28.

17. Algoriness RM, Alqahtani NT, Aljarbou AM, AlShammari RS, Alrashidi AG, et al. Prevalence of myopia and its related risk factors among medical students in Saudia Arabia. Adv Ophthalmol Vis Syst. 2017; 6(1): 00165.

18. Ip JM, Huynh SC, Robaei D, Rose KA, Morgan IG, et al. Ethnic differences in the impact of parental myopia: findings from a populationbased study of 12-year-old Australian children. Invest Ophthalmol Vis Sci. 2007; 48(6): 2520-8. 
19. Alam M. ABO and Rhesus blood groups in potential blood donors at Skardu (Northern Areas). Pak J Pathol. 2005; 16: 94-7.

20. Nazli R, Haider J, Khan MA, Akhtar T, Aslam $\mathrm{H}$. Frequency of $\mathrm{ABO}$ blood groups and $\mathrm{RhD}$ factor in the female population of District Peshawar. Pak J Med Sci 2015; 31(4): 984-986.

21. Khaskheli DK, Qureshi AH, Akhund AA. Distribution of $\mathrm{ABO}$ and $\mathrm{Rh}$ groups in the residents of Sindh. Pak J Health. 1994;31:45-50.

22. Hussain A, Shiekh SA, Haider M, Rasheed T, Malik MR. Frequency of ABO and Rh blood groups in population of Balouchistan (Pakistan). Pak Armed Forces Med J. 2001; 51:22-26.

23. Khan MS, Farooq N, Qamar N, Tahir F, Subhan F,Kazi BM et al. Trend of blood groups and $\mathrm{Rh}$ Factor in twin cities of RawalpindiIslamabad. J Pak Med Assoc. 2006;56(7):299-302

\section{The Authors:}

Dr. Shazo Sana

Demonstrator,

Department of Physiology,

Fatima Jinnah Medical University, Lahore.
Prof. Dr. Shireen Khawar

Head of Physiology Department,

Fatima Jinnah Medical University, Lahore.

Dr. Hafiz Muhammad Umair

Senior Demonstrator,

Department of Hematology,

Fatima Jinnah Medical University, Lahore.

Dr. Ghazala Naveed

Associate professor,

Department of Physiology,

Fatima Jinnah Medical University, Lahore.

Dr. Maryam Rao

Assistant Professor,

Department of Physiology,

Fatima Jinnah Medical University, Lahore.

\section{Corresponding Author:}

Dr. Shazo Sana

Demonstrator,

Department of Physiology,

Fatima Jinnah Medical University, Lahore.

E-mail: shazirose2011@hotmail.com 